\title{
STUDY ON PERSISTENT UTERINE ARTERY DIASTOLIC NOTCH: A PREDICTOR OF HYPERTENSIVE DISORDERS OF PREGNANCY AND FOETAL GROWTH RESTRICTION
}

\author{
Umarani Pachamuthu1, Mohana Dhanapal2, Vijaya Subramanian ${ }^{3}$ \\ ${ }^{1}$ Assistant Professor, Department of Obstetrics \& Gynaecology, Madras Medical College. \\ ${ }^{2}$ Senior Assistant Professor, Department of Obstetrics \& Gynaecology, Madras Medical College. \\ 3Professor, Department of Obstetrics \& Gynaecology, Madras Medical College.
}

\begin{abstract}
\section{BACKGROUND}

Hypertensive disorders complicating pregnancy are common and form one of the deadly triad along with haemorrhage and infection that contribute greatly to maternal morbidity, mortality and responsible for $20 \%$ of perinatal mortality and morbidity. Incidence of foetal growth restriction is close to $10 \%$ of all births and contributes to increased perinatal morbidity and mortality. This prospective study is on persistent uterine artery diastolic notch as a predictor of hypertensive disorders of pregnancy and foetal growth restriction.
\end{abstract}

\section{METHODS}

The study population consisted of 200 antenatal women attending outpatient clinic, Institute of Social Obstetrics and Government Kasturba Gandhi Hospital with the 16-28 weeks of gestation.

\section{RESULTS}

Persistence of notch was seen in $27.17 \%$ of cases. Among them $47.16 \%$ of cases had hypertensive disorders of pregnancy, $39.62 \%$ of cases had foetal growth restriction, $22.64 \%$ of cases had FGR with HTD.

\section{CONCLUSION}

This study highlights that the persistence of uterine artery diastolic notch, especially bilateral notch should be specifically evaluated so that necessary timely intervention can be made. Persistent uterine artery notch in high risk women is a good predictor of hypertensive disorders of pregnancy and foetal growth restriction.

\section{KEYWORDS}

Hypertensive Disorders of Disorders of Pregnancy, Foetal Growth Restriction, Uterine Artery Diastolic Notch.

HOW TO CITE THIS ARTICLE: Pachamuthu U, Dhanapal M, Subramanian V. Study on persistent uterine artery diastolic notch: a predictor of hypertensive disorders of pregnancy and foetal growth restriction. J. Evolution Med. Dent. Sci. 2016;5(58):3988-3994, DOI: $10.14260 /$ jemds/2016/913

\section{INTRODUCTION}

Uteroplacental bed perfusion increases in normal pregnancy and decreases in foetal growth restriction and hypertensive disorders of pregnancy. ${ }^{1}$ The alterations in the uteroplacental circulations precedes the onset of foetal growth restriction and hypertensive disorders of pregnancy.

Doppler ultrasound is an innovation in foetal surveillance, which would indicate the state of uteroplacental and fetoplacental blood flow from which implications about the foetal condition can be made. ${ }^{2}$

Uterine artery flow velocity wave forms recorded throughout the menstrual cycle and early pregnancy are usually characterized by an early diastolic notch, which indicates high resistant uterine blood flow. In normal pregnancies, the early diastolic notch persists until approximately 24 weeks gestation and it is rarely recorded

Financial or Other, Competing Interest: None.

Submission 18-04-2016, Peer Review 30-05-2016,

Acceptance 07-06-2016, Published 19-07-2016.

Corresponding Author:

Dr. Umarani Pachamuthu,

Assistant Professor,

Department of Obstetrics \& Gynaecology,

The Atlantic, No: 3, Montieth Road,

Egmore, Chennai-600008,

Tamilnadu.

E-mail:dr_uma78@yahoo.com

DOI: $10.14260 /$ jemds $/ 2016 / 913$ on placental side after 24 weeks due to conversion of high resistance uterine blood flow to low resistance flow. FGR and hypertensive disorders of pregnancy is due to defective placentation, which leads to persistence of diastolic notch.

Ramsay and Donner (1980) presented a summary of their anatomical studies of the uteroplacental vasculature. The first wave occurs before 12 weeks post fertilization and consists of invasion and modification of the spiral arteries of the decidua, reaching its border with the myometrium. Between 12-16 weeks post fertilization, the second wave occurs. This involves invasion of the intramyometrial parts of the spiral arteries converting narrow lumen, muscular spiral arteries into dilated, low resistance uteroplacental vessels and decreased responsiveness to pressor substances. A lack of endovascular infiltration by trophoblasts into the myometrial portion of the placental bed spiral arteries results in persistence of high resistance flow and early diastolic notch. Defective trophoblastic invasion is the consistent finding in hypertensive disorder/FGR.

To evaluate uterine artery Doppler wave forms, colour flow mapping is used to locate the uterine arteries as they cross from medial to the iliac arteries.

The Doppler gate is placed within the straight portion of uterine artery before it enters the myometrium.

Hence, this study is done to predict the occurrence of these two disorders by using persistence of uterine artery diastolic notch. 


\section{AIM AND OBJECTIVE}

To find out the correlation between persistence of uterine artery diastolic notch by Doppler and development of foetal growth restriction and hypertensive disorders of pregnancy.

\section{MATERIALS AND METHODS}

Study Design: Prospective study.

Study Period: July 2012 to June 2014.

\section{Sample Population}

The antenatal mothers were clinically evaluated at the Antenatal OP Department and were allocated into two groups as follows.

Group I: 100 antenatal mothers at 16-28 weeks primi/multi. Group II: 100 antenatal mothers at 16-28 weeks with previous history of FGR/hypertensive disorders of pregnancy.

\section{Inclusion Criteria \\ Group I}

Antenatal mothers primi/multi without any previous $\mathrm{H} / \mathrm{O}$ FGR/Hypertensive disorders of pregnancy/IUD.

\section{Group II}

Antenatal mothers with previous H/O FGR/Hypertensive disorders of pregnancy.

\section{Exclusion Criteria}

1. Women with medical disorders complicating pregnancy like diabetes, cardiac diseases, chronic hypertension, SLE complicating pregnancy, chronic renal disease.

2. Multiple gestation.

3. Women with congenitally malformed fetus.

\section{Method of Study}

An mothers were registered at 16 wks. for basic evaluation. For all mothers a thorough general, obstetric history was elicited and a complete general, obstetric examination was done. All the basic investigations were done. Uterine artery Doppler was done between 24 \& 28 weeks of gestation. Doppler characteristics evaluated for predicting foetal growth restriction/hypertensive disorders of pregnancy was persistence of uterine artery diastolic notch.

\section{Method of Doppler Study}

The selected cases are subjected to a colour Doppler which included biometry, Doppler evaluation for persistence of diastolic notches in the uterine arteries of both sides. The Doppler equipment consisted of a colour Doppler system with a carrier frequency of 3.5 MHZ. The Doppler evaluation was carried out as follows. Antenatal mother is placed in a supine, slightly left lateral position and wedge is placed under the left flank. It is important to avoid supine hypotension syndrome due to vena caval compression. For uterine artery Doppler, the probe is placed $2-3 \mathrm{~cm}$ medial to the anterior superior iliac spine.

The transducer is pointed laterally and downward toward the parametrial area where the iliac vessels pierce the myometrium.

The presence of diastolic notch was noted. Main outcome variables for analysis were the development of hypertension with or without proteinuria, FGR, mode of delivery, gestational age at delivery and perinatal outcome.

\section{RESULTS AND ANALYSIS}

In group I 100 cases and in group II 100 cases were selected and prospectively followed up; 3 cases in group I and 2 cases in group II were lost for followup. These cases not reported back after Doppler study. The selected cases had uterine artery evaluation between 24-28 weeks gestation and followed up for development of hypertensive disorders, foetal growth restriction, gestational age at delivery, mode of delivery and perinatal outcome. Cases included were mainly belonging to class IV/class V socioeconomic status.

\section{The following Observations were made}

\begin{tabular}{|c|c|c|}
\hline \multirow{2}{*}{ Age } & \multicolumn{2}{|c|}{ No. of Cases } \\
\cline { 2 - 3 } & Group I & Group II \\
\hline $18-20$ yrs. & $27(27.8 \%)$ & $13(13.2 \%)$ \\
\hline $21-30$ yrs. & $66(68 \%)$ & $76(77.5 \%)$ \\
\hline $31-35$ yrs. & $4(4.1 \%)$ & $9(9.1 \%)$ \\
\hline \multicolumn{2}{|c|}{ Table I: Age Distribution of Cases } \\
\hline
\end{tabular}

In this study, 66 cases (68\%) in group I and 76 cases (77.5\%) in group II belonged to the age group of 21-30 yrs.; 27 cases $(27.8 \%)$ in group I and 13 cases $(13.2 \%)$ in group II belonged to the age group of $18-20$ yrs. and the remaining belonged to the age group of 31- 35 years.

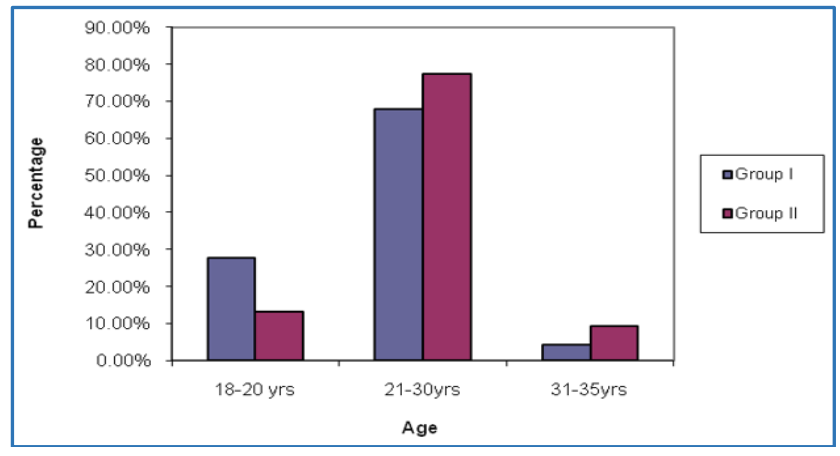

Fig. 1: Age Distribution of Cases

Table II: Group I

\begin{tabular}{|c|c|c|}
\hline Parity & Count & $\mathbf{\%}$ \\
\hline Multi & 31 & 31.96 \\
\hline Primi & 66 & 68.04 \\
\hline Total & $\mathbf{9 7}$ & $\mathbf{1 0 0}$ \\
\hline \multicolumn{2}{|r|}{ Table II: Parity Distribution of Cases } \\
\hline
\end{tabular}

In Group I, 66 cases (68.04\%) were primi gravida and 31 cases $(31.96 \%)$ were multigravida.

\section{Table III: Group II}

\begin{tabular}{|c|c|c|}
\hline Parity & Count & \% \\
\hline Multi & 98 & 100 \\
\hline Primi & 0 & 0 \\
\hline Total & $\mathbf{9 8}$ & $\mathbf{1 0 0}$ \\
\hline
\end{tabular}

In Group II, all were multigravida 98 cases (100\%). 


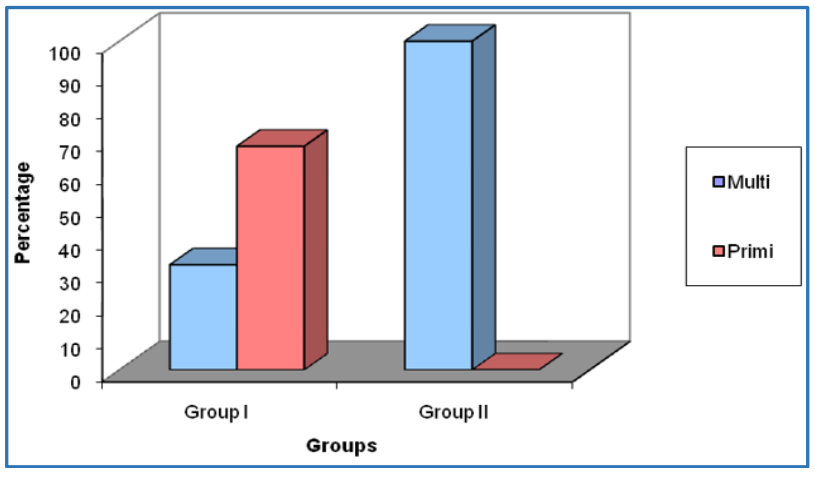

Fig. 2: Parity Distribution of Cases

Notch Distribution

Table IV: Group - I

\begin{tabular}{|c|c|c|}
\hline Notch & Count & \% \\
\hline Absent & 75 & 77.32 \\
\hline Bilateral & 11 & 11.34 \\
\hline Unilateral & 11 & 11.34 \\
\hline Total & $\mathbf{9 7}$ & $\mathbf{1 0 0}$ \\
\hline
\end{tabular}

In Group I, bilateral notch was present in 11 cases $(11.34 \%)$ and unilateral notch was present in 11 cases (11.34\%).

\section{Table V: Group - II}

\begin{tabular}{|l|c|c|}
\hline \multicolumn{1}{|c|}{ Notch } & Count & \% \\
\hline Absent & 67 & 68.37 \\
\hline Bilateral & 24 & 24.49 \\
\hline Unilateral & 7 & 7.14 \\
\hline Total & $\mathbf{9 8}$ & $\mathbf{1 0 0}$ \\
\hline
\end{tabular}

In Group II, bilateral notch was present in 24 cases $(24.49 \%)$ and unilateral notch was present in 7 cases (7.14\%).

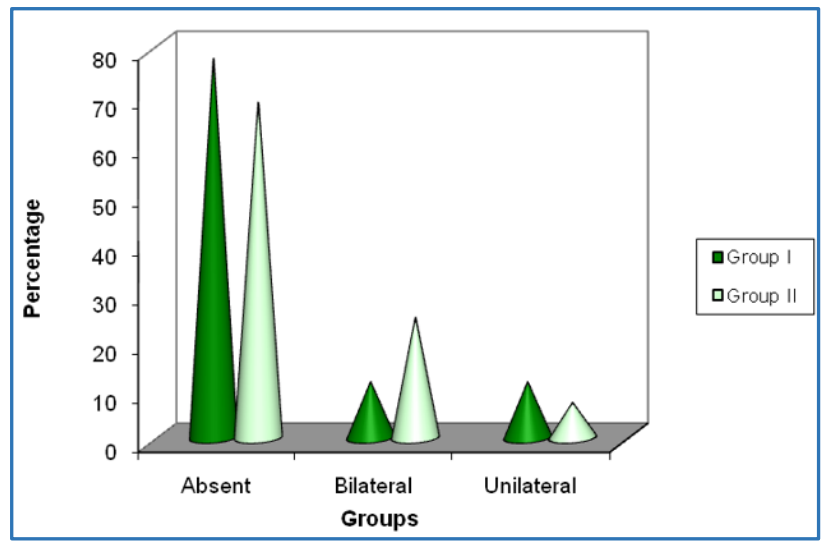

Fig. 3: Notch Distribution

\section{NOTCH AND HTD/FGR}

Table VI: Group - I

\begin{tabular}{|c|c|c|c|c|}
\hline Notch & Number & Normal Outcome & HTD & FGR \\
\hline \multirow{2}{*}{ Bilateral } & 11 & 6 & 4 & 3 \\
& $(11.34 \%)$ & $(54.5 \%)$ & $(36.36 \%)$ & $(27.27 \%)$ \\
\hline \multirow{2}{*}{ Unilateral } & 11 & 7 & 2 & 2 \\
& $(11.34 \%)$ & $(63.63 \%)$ & $(18.18 \%)$ & $(18.18 \%)$ \\
\hline \multirow{2}{*}{ Total } & 22 & 13 & 6 & 5 \\
& $(22.68 \%)$ & $(59.09 \%)$ & $(27.27 \%)$ & $(22.72 \%)$ \\
\hline \multirow{2}{*}{ Absent } & 75 & 72 & 2 & 1 \\
& $(77.31 \%)$ & $(96 \%)$ & $(2.6 \%)$ & $(1.3 \%)$ \\
\hline
\end{tabular}

In group I, 4 cases (36.36\%) had HTD, 3 cases $(27.27 \%)$ had FGR in the cases with persistence of bilateral uterine artery notch.

In group I, 2 cases (18.18\%) had HTD, 2 cases $(18.18 \%)$ had FGR in the case with persistence of unilateral uterine artery notch.

In group I, 2 cases $(2.6 \%)$ had HTD and 1 case $(1.3 \%)$ had FGR in the absence of notch.

\section{Group I}

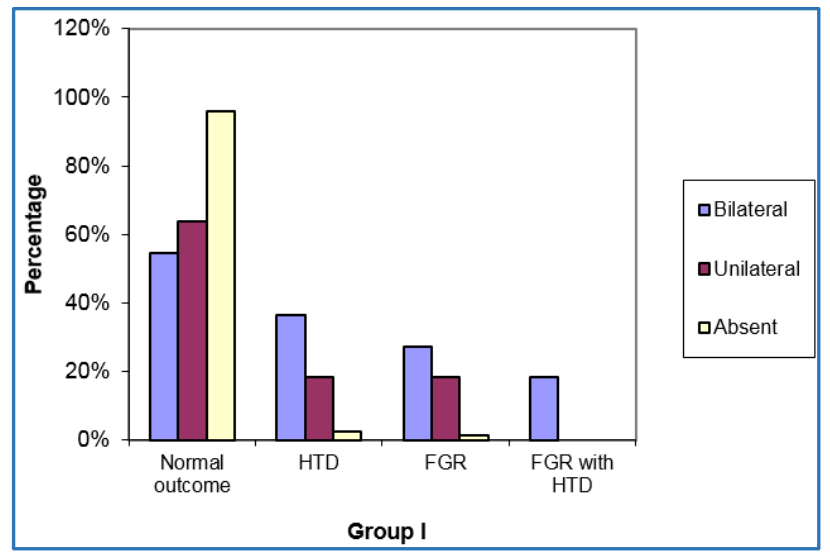

Fig. 4: Notch and HTD/FGR

Table VII: Group - II

\begin{tabular}{|c|c|c|c|c|}
\hline Notch & Number & $\begin{array}{c}\text { Normal } \\
\text { Outcome }\end{array}$ & HTD & FGR \\
\hline \multirow{2}{*}{ Bilateral } & $\begin{array}{c}24 \\
(24.49 \%)\end{array}$ & $\begin{array}{c}5 \\
(20.8 \%)\end{array}$ & $\begin{array}{c}14 \\
(58.33 \%)\end{array}$ & $\begin{array}{c}14 \\
(58.33 \%)\end{array}$ \\
\hline Unilateral & $\begin{array}{c}7 \\
(7.14 \%)\end{array}$ & $\begin{array}{c}1 \\
(14.28 \%)\end{array}$ & $\begin{array}{c}5 \\
(71.4 \%)\end{array}$ & $\begin{array}{c}2 \\
(28.57 \%)\end{array}$ \\
\hline \multirow{2}{*}{ Total } & $\begin{array}{c}31 \\
(31.6 \%)\end{array}$ & $\begin{array}{c}6 \\
(19.35 \%)\end{array}$ & $\begin{array}{c}19 \\
(61.22 \%)\end{array}$ & $\begin{array}{c}16 \\
(51.61 \%)\end{array}$ \\
\hline \multirow{2}{*}{ Absent } & $\begin{array}{c}67 \\
(68.36 \%)\end{array}$ & $\begin{array}{c}62 \\
(92.53 \%)\end{array}$ & $\begin{array}{c}3 \\
(4.4 \%)\end{array}$ & $\begin{array}{c}2 \\
(2.98 \%)\end{array}$ \\
\hline
\end{tabular}

In group II, 14 cases (58.33\%) had HTD, 14 cases had FGR in the cases of persistence of bilateral uterine artery notch.

In group II, 5 cases (71.4\%) had HTD, 2 cases $(28.57 \%)$ had FGR in the cases of persistence of unilateral uterine artery notch.

In the absence of notch 3 cases (4.4\%) had HTD and 2 cases $(2.9 \%)$ had FGR.

\section{Group - II}

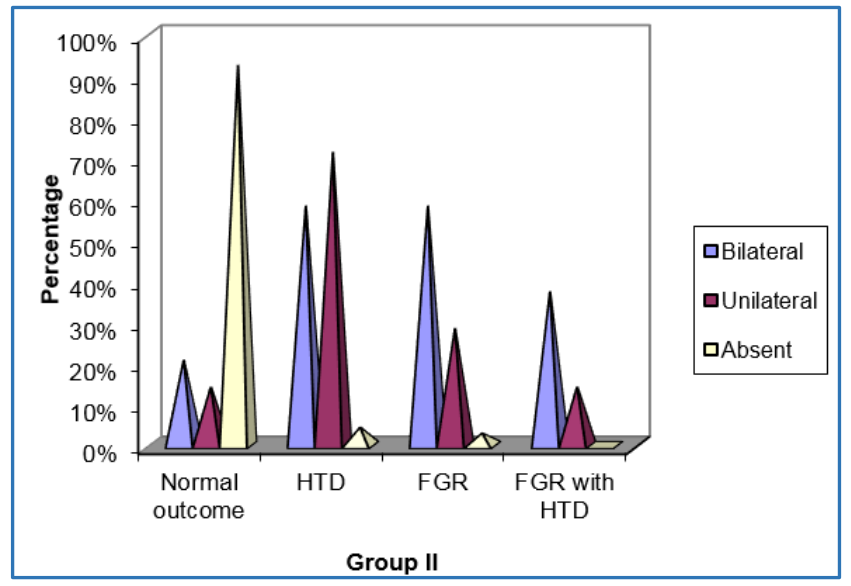

Notch and HTD/FGR 


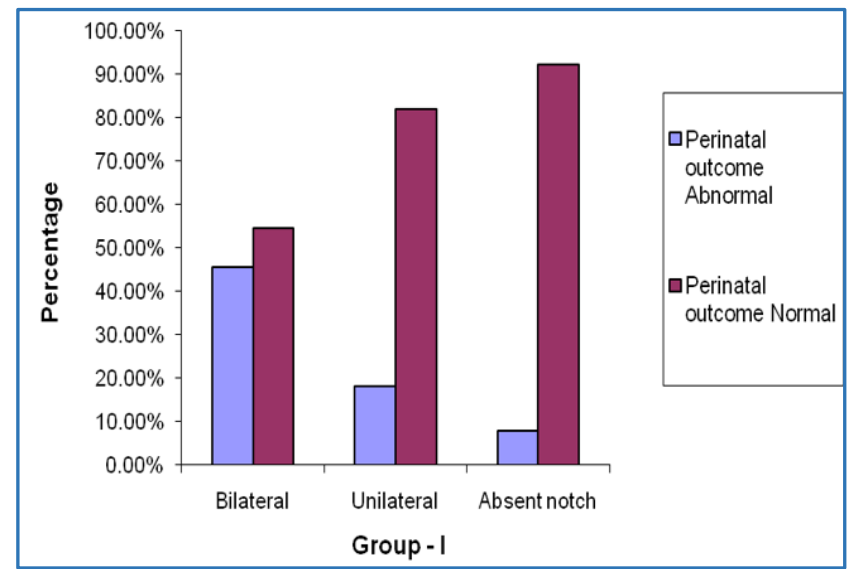

Fig. 5: Notch and Perinatal Outcome

Table VII: Group I

\begin{tabular}{|c|c|c|c|}
\hline \multirow{2}{*}{ Notch } & \multirow{2}{*}{$\begin{array}{c}\text { Number } \\
\text { of Cases }\end{array}$} & \multicolumn{2}{|c|}{ Perinatal Outcome } \\
\cline { 3 - 4 } & 11 & Abnormal & Normal \\
\hline Bilateral & 11 & $2(45.45 \%)$ & $6(54.54 \%)$ \\
\hline Unilateral & 22 & $7(31.81)$ & $15(81.81 \%)$ \\
\hline Total & 75 & $6(8 \%)$ & $69(92 \%)$ \\
\hline $\begin{array}{c}\text { Absent } \\
\text { Notch }\end{array}$ & $75 \%)$ \\
\hline
\end{tabular}

\section{CONCLUSION}

In Group I, in the presence of bilateral notch, 5 cases $(45.45 \%)$ had abnormal perinatal outcome and in the presence of unilateral notch 2 cases $(18.18 \%)$ had abnormal perinatal outcome.

Abnormal perinatal outcome was noted as Apgar $<7 / 10$, Meconium aspiration syndrome, respiratory distress, small for gestational age, preterm delivery and its complications, NICU admission.

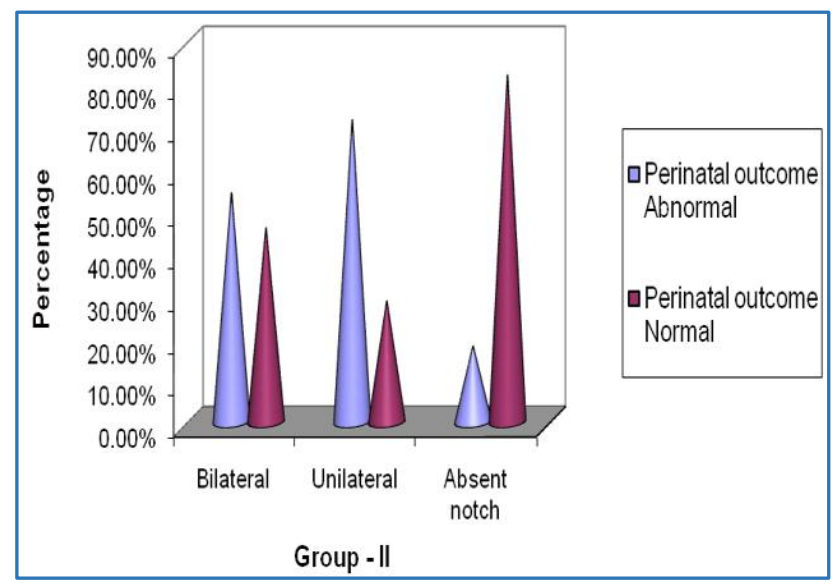

Group - II: Persistence of Notch and Perinatal Outcome Group - I Group II

\begin{tabular}{|c|c|c|c|}
\hline \multirow{2}{*}{ Notch } & \multirow{2}{*}{$\begin{array}{c}\text { Number } \\
\text { of Cases }\end{array}$} & \multicolumn{2}{|c|}{ Perinatal Outcome } \\
\cline { 3 - 4 } & 24 & $13(54.16 \%)$ & $11(45.83 \%)$ \\
\hline Bilateral & 7 & $5(71.42 \%)$ & $2(28.57 \%)$ \\
\hline Unilateral & 7 & $18(58.06 \%)$ & $13(41.93 \%)$ \\
\hline Total & 31 & $12(17.9 \%)$ & $55(82.03 \%)$ \\
\hline Absent Notch & 67 &
\end{tabular}

\section{CONCLUSION}

In Group II, in the presence of bilateral notch, 13 cases (54.16\%) had abnormal perinatal outcome and in the presence of unilateral notch 5 cases $(71.42 \%)$ had abnormal perinatal outcome.

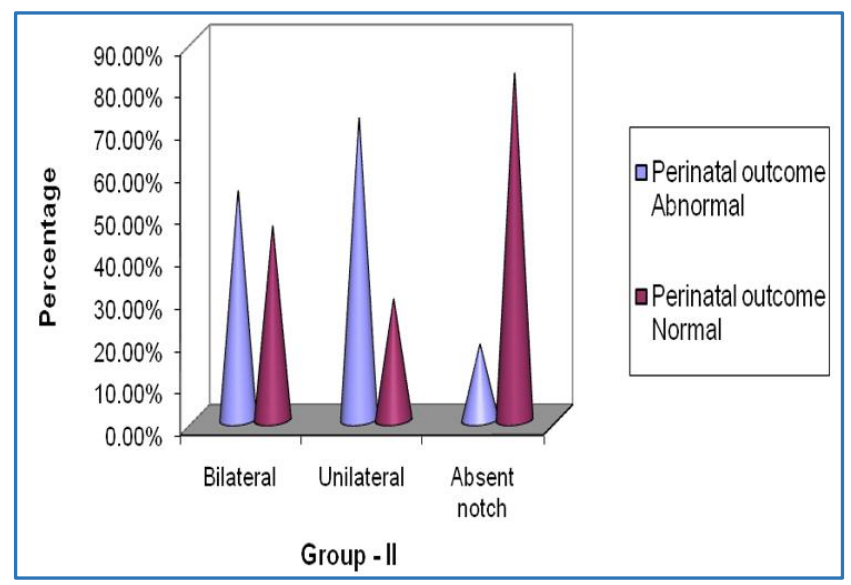

\section{Persistence of Notch and Perinatal Outcome Group - II}

\section{DISCUSSION}

Doppler velocimetry is a non-invasive technic, which uses high frequency sound for the investigation of blood flow. The feasibility of its foetal application was first reported by Fitzgerald and Drumm. ${ }^{3}$ It made non-invasive investigation of uteroplacental circulation possible. Diastolic notch is defined as the slower velocity just after systolic flow, but before maximum diastolic flow.

In this study, there was statistically significant association between the persistence of both unilateral, bilateral notching and development of hypertensive disorders of pregnancy, foetal growth restriction when compared to notch absent groups.

In Group I, 36.36\% had HTD of pregnancy and $27.27 \%$ had FGR in the presence of bilateral notch, $18.18 \%$ had HTD and $18.18 \%$ had FGR in the presence of unilateral notch. In Group II, 58.33\% had HTD and 58.33\% had FGR in the presence of bilateral notch and $71.4 \%$ had HTD and $28.57 \%$ had FGR in the presence of unilateral notch.

Persistence of bilateral notching was associated significantly with severe forms of hypertensive disorders of pregnancy (31.42\%) when compared to unilateral notching (5.5\%).

A prospective trial of Zimmermann et $\mathrm{al}^{4}$ evaluated the utility of uterine artery Doppler between 21-24 wks. in the prediction of preeclampsia and FGR. He selected 172 low risk pregnancies and 175 women at risk for hypertensive disorders of pregnancy/FGR. Presence of persistent notch accounted for 3-4 fold increased risk in developing preeclampsia/FGR. In this group, preeclampsia/FGR was found in $58.3 \%$ compared to $8.3 \%$ if Doppler results were normal. Doppler was less informative in low risk population. Here preeclampsia/FGR were $6.1-6.4 \%$ in this low risk group and $5.2 \%$ in notch absent group.

Deutinger et al believed that early diastolic notch persistence was thought to represent the persistence of inherent total impedance of the uteroplacental circulation. 
Rofinas et $\mathrm{al}^{5}$ found that the persistence of uterine artery diastolic notch indicates severe hypertensive disorder and associated with increased rate of FGR, caesarean delivery, foetal distress and preterm delivery.

In 1983, Campbell et al ${ }^{6}$ was the first to demonstrate a correlation between pregnancies complicated by hypertensive disorder/FGR, increased caesarean rate, foetal distress, low APGAR scores and persistence of uterine artery notch. Furthermore, proteinuria and severe hypertension correlated significantly with persistent notch.

Flesicher et $\mathrm{al}^{7}$ in 1986 demonstrated the presence of an early diastolic notch in the uterine artery after 26 weeks gestation correlated significantly with the clinical diagnosis of preeclampsia, abnormal perinatal outcome, increased caesarean rate.

Trudinger. 8 in 1990 did Doppler uterine artery in a highly selected population for prediction of severe PIH.

Thaler et al, demonstrated the persistence of an early diastolic notch after 26 weeks of gestation in $25-40 \%$ of preeclampsia. Presence of notch is significantly a better predictor of poor pregnancy than the S/D ratio (or) resistive index.

Pai. ${ }^{9}$ found persistent diastolic notch to be a better parameter than abnormal RI in predicting the hypertensive disorders of pregnancy/foetal growth restriction.

Bower. 10 et al also predicted the hypertensive disorders of pregnancy/foetal growth restriction by persistence of uterine artery notch.

Aristidou et al noted that the uterine artery notch was a good predictor of poor perinatal outcome, increased rate of FGR, caesarean delivery for foetal distress, preterm delivery.

In 2001, Christopher Lees carried out a colour Doppler assessment of uterine artery in 5121 women attending routine antenatal clinic and concluded that persistent uterine artery notch associated with adverse perinatal outcome.

Validity of tests in Group I and II for any notch and bilateral notch for hypertensive disorder/foetal growth restriction when compared to other studies were,

For Prediction of Hypertensive Disorders

\begin{tabular}{|c|c|c|c|c|}
\hline Author & Sensitivity\% & Specificity\% & Positive Predictive Value & Negative Predictive Value \\
\hline Pai. $^{9}$ & 45.45 & 92 & 38 & 93.87 \\
\hline Bower et al $^{10}$ & 78 & 96 & 28 & 99.5 \\
\hline Agarwal. $^{11}$ & 84 & 71.4 & 72 & - \\
\hline May Backos et al $^{12}$ & 38 & 85 & 27 & 90 \\
\hline Papageorghiou et al $^{13}$ & 41 & - & - & - \\
\hline
\end{tabular}

In this study, Group I

\begin{tabular}{|c|c|c|c|c|c|c|c|c|}
\hline Notch & Sensitivity & Specificity & $\begin{array}{c}\text { Positive } \\
\text { Predictive } \\
\text { Value }\end{array}$ & $\begin{array}{c}\text { Negative } \\
\text { Predictive } \\
\text { Value }\end{array}$ & $\begin{array}{c}\text { LR for } \\
\text { + Test }\end{array}$ & $\begin{array}{c}\text { LR for } \\
- \text { Test }\end{array}$ & FP & FN \\
\hline Any notch & $\mathbf{7 5 \%}$ & $82.0 \%$ & $27.27 \%$ & $97.33 \%$ & 4.16 & 0.3 & $6.7 \%$ & $25 \%$ \\
\hline Bilateral & $\mathbf{6 6 \%}$ & $92 \%$ & $36 \%$ & $97.67 \%$ & 8.25 & 0.36 & $7.61 \%$ & $33.3 \%$ \\
\hline
\end{tabular}

\section{Group II}

\begin{tabular}{|c|c|c|c|c|c|c|c|c|}
\hline Notch & Sensitivity & Specificity & $\begin{array}{c}\text { Positive } \\
\text { Predictive } \\
\text { Value }\end{array}$ & $\begin{array}{c}\text { Negative } \\
\text { Predictive } \\
\text { Value }\end{array}$ & $\begin{array}{c}\text { LR } \\
\text { for + } \\
\text { Test }\end{array}$ & $\begin{array}{c}\text { LR } \\
\text { for }-\end{array}$ & FP & FN \\
\hline Any notch & $86.36 \%$ & $84.21 \%$ & $61.29 \%$ & $95.52 \%$ & 5.46 & 0.16 & $15.78 \%$ & $13.63 \%$ \\
\hline Bilateral & $82.34 \%$ & $87.65 \%$ & $58.33 \%$ & $95.94 \%$ & 6.66 & 0.2 & $12.34 \%$ & $21.42 \%$ \\
\hline
\end{tabular}

For Prediction of Foetal Growth Restriction

\begin{tabular}{|c|c|c|c|c|}
\hline Author & Sensitivity & Specificity & $\begin{array}{c}\text { Positive } \\
\text { Predictive Value }\end{array}$ & $\begin{array}{c}\text { Negative } \\
\text { Predictive Value }\end{array}$ \\
\hline${\text { Papageorghiou et al }{ }^{13}}^{\text {May Backos et al }}{ }^{14}$ & $24 \%$ & - & & \\
\hline
\end{tabular}

Group I

\begin{tabular}{|c|c|c|c|c|c|c|c|c|}
\hline Notch & Sensi & Speci & $\begin{array}{c}\text { Positive } \\
\text { Predictive } \\
\text { Value }\end{array}$ & $\begin{array}{c}\text { Negative } \\
\text { Predictive } \\
\text { Value }\end{array}$ & $\begin{array}{c}\text { LR } \\
\text { for + } \\
\text { test }\end{array}$ & $\begin{array}{l}\text { LR } \\
\text { for - } \\
\text { test }\end{array}$ & FP & FN \\
\hline Any notch & $83.33 \%$ & $81.31 \%$ & $22.7 \%$ & $98.66 \%$ & 4.36 & 0.2 & $18.68 \%$ & $16.66 \%$ \\
\hline Bilateral & $75 \%$ & $91.39 \%$ & $27.27 \%$ & $98.83 \%$ & 8.3 & 0.27 & $8.6 \%$ & $25 \%$ \\
\hline
\end{tabular}

\section{Group II}

\begin{tabular}{|c|c|c|c|c|c|c|c|c|}
\hline Notch & Sensi & Speci & $\begin{array}{c}\text { Positive } \\
\text { Predictive } \\
\text { Value }\end{array}$ & $\begin{array}{c}\text { Negative } \\
\text { Predictive } \\
\text { Value }\end{array}$ & $\begin{array}{c}\text { LR } \\
\text { for }+ \\
\text { Test }\end{array}$ & $\begin{array}{c}\text { LR } \\
\text { for }- \\
\text { Test }\end{array}$ & FP & FN \\
\hline Any notch & $88.8 \%$ & $81.25 \%$ & $51.61 \%$ & $97.01 \%$ & 4.74 & 0.13 & $18.75 \%$ & $11.11 \%$ \\
\hline Bilateral & $87.5 \%$ & $87.80 \%$ & $58.3 \%$ & $97.29 \%$ & 7.17 & 0.14 & $12.1 \%$ & $12.5 \%$ \\
\hline
\end{tabular}


The most useful part of the test is the negative predictive value. A negative test at 24 wks. in a high risk population indicates a $97-99 \%$ probability that HTD/FGR will not be present. ${ }^{10}$ So in the absence of notch, reassurance can be given to the high risk cases.

Valensise et al 1993.15 has better sensitivity of $88 \%$ for the prediction of preeclampsia. Conde-Agudelo et al 1993.16 found that the sensitivity of the test was $72-92 \%$ in prediction of hypertensive disorders of pregnancy. On evaluating the likelihood ratio for positive and negative tests, presence of any notch is mild predictor of these disorders in group I and was moderate predictor of hypertensive disorders/foetal growth restriction in group II.

It can be evaluated along with routine scan in all women if possible. But in high risk women, it should be specifically evaluated for better antenatal care so that necessary timely intervention can be done.

Several factors are likely to influence the performance of screening tests and these include anatomical site of measurement of uterine artery Doppler. Test to be done at standard reference point for better prediction.

\section{SUMMARY}

\section{In Group - I}

- $68 \%$ of cases belonged to 21-30 yrs. of age.

- $68.04 \%$ of cases were primigravida and $31.96 \%$ were multigravida.

- Bilateral notch was present in $11.34 \%$ of cases (primi$81.81 \%$, multi- $18.18 \%$ ).

- Unilateral notch was present in $11.34 \%$ of cases (primi$72.72 \%$, multi- $27.27 \%$ ).

- $36.36 \%$ of cases had hypertensive disorders of pregnancy, $27.27 \%$ of cases had foetal growth restriction, $18.18 \%$ of cases had hypertensive disorder with foetal growth restriction, $36.36 \%$ had caesarean delivery, $27.27 \%$ of cases had preterm delivery, $45.45 \%$ had abnormal perinatal outcome in the presence of bilateral notch.

- In cases with unilateral notch, $18.18 \%$ of cases had hypertensive disorders of pregnancy, $18.18 \%$ of cases had foetal growth restriction, $18.18 \%$ had caesarean delivery, $9.09 \%$ had preterm delivery, $18.18 \%$ had abnormal perinatal outcome.

- In the absence of notch, $2.6 \%$ of cases had hypertensive disorders, $1.3 \%$ cases had foetal growth restriction, $16 \%$ had caesarean section, $10.66 \%$ had preterm delivery, $8 \%$ had abnormal perinatal outcome. There is significant association between notch and HTD, FGR, abnormal perinatal outcome, mode of delivery and no significant association between notch and HTD with FGR, gestational age at delivery. In the presence of notch, there is increased incidence of HTD, FGR, caesarean delivery.

\section{In Group II}

- $77.5 \%$ of cases belonged to the age group of 21 to 30 years of age.

- $100 \%$ were multigravida.

- Bilateral notch was present in $24.49 \%$ of cases.

- Unilateral notch was present in $7.14 \%$ of cases.

- In the presence of bilateral notch, $58.33 \%$ had hypertensive disorders, $58.33 \%$ had foetal growth restriction, $37.5 \%$ had hypertensive term delivery, abnormal perinatal outcome disorders with foetal growth restriction, $41.66 \%$ had caesarean delivery, $16 \%$ had preterm delivery, $54.16 \%$ had abnormal perinatal outcome.

- In the presence of unilateral notch $71.4 \%$ had hypertensive disorders, $28.57 \%$ had foetal growth restriction, $14.28 \%$ had hypertensive disorders with foetal growth restriction, $57.14 \%$ had caesarean delivery, $14.28 \%$ had preterm delivery, $71.42 \%$ had abnormal perinatal outcome.

- There is significant association between notch and HTD, FGR, abnormal perinatal outcome, mode of delivery, HTD with FGR, gestational age at delivery. In the presence of notch, there is increased incidence of HTD, FGR, caesarean delivery, preterm delivery, abnormal perinatal outcome.

\section{CONCLUSION}

1. Persistent uterine artery notch is a predictor of development of hypertensive disorders of pregnancy and foetal growth restriction. Presence of bilateral notch is significantly associated with severe form of hypertensive disorders.

2. In high risk pregnancies, an abnormal uterine artery Doppler is an indication for a closer antenatal followup and normal uterine artery Doppler is reassuring and allows less frequent foetal surveillance when compared to positive test.

3. To improve the predictive value of tests, it can be combined with clinical high risk factors, also with estimation of serum inhibin A, serum $\beta$ HCG concentration.

4. In developing countries like India, cost effectiveness of the tests should also be taken into consideration.

5. Hence in high risk women, persistence of uterine artery notch especially bilateral notch should be specifically evaluated so that necessary timely intervention can be made. Persistent uterine artery notch in high risk women is a good predictor of hypertensive disorders of pregnancy and FGR.

\section{REFERENCES}

1. Brosens I, Robertson WB, Dixon HG. The physiological response of the vessels of the placental bed to normal pregnancy. J Pathol Bacteriol 1967;93(2):569-791.

2. Schulman H, Ducey J, Farmakides G, et at. The significance of divergent systolic-diastolic ratios. Am J Obstet Gynaecol 1987;157(6):1539-42.

3. Fitzgerald DE, Drumm JE. Non-invasive measurement of human foetal circulation using USG: a new method. BMJ 1977;2(6100):1450-1.

4. Zimmermann P, Eirio V, Koskinen J, et al. Doppler assessment of the uterine and uteroplacental circulation in the second trimester in pregnancies at high risk for preeclampsia or intrauterine growth retardation: comparison between different Doppler parameter Ultrasound Obstetrics Gynaecology 1997;9(5):330-8.

5. Gudnasson HM, Dubiel M, Gudmundsson S. Preeclampsia-abnormal uterine artery Doppler is related to recurrence of symptoms during next pregnancy. J Perinat Med 2004;32(5):400-3. 
6. Campbell S, Bewley S, Cohen T. Investigation of the uteroplacental circulation by Doppler ultrasound. Semin Perinatol 1987;11(4):362 -8.

7. Sroff JW, Tonge HM, Stewart PA. Doppler USG assessment of uterine art flow in fetus. $\mathrm{Br} \mathrm{J}$ Obs Gynaecol 1986;93:470-5.

8. Trudinger B, Cook CM. Umbilical and uterine art flow velocity wave forms in pregnancy associated with major congenital abnormality. Br J Obs Gyn 1985;92:666.

9. Pai MV. Improved prediction of PIH and IUGR by 2 stage screening of uterine artery Doppler velocimetry. Ind J Med USG 2001;2:64-9.

10. Bower S, Bewley S, Campbell S. Improved prediction of preeclampsia by 2 stage screening of the uterine arteries using the early diastolic notch and colour Doppler imaging. Obs Gyn 1993;82(1):78-83.

11. Agarwal P, Rajeev AK. Persistence uterine artery notch-a predictor of IUGR/PIH. J Obs Gyn India 2006;56(4): 301-3.
12. Venkat-Raman N, Backos $\mathrm{M}, \mathrm{Teoh} \mathrm{TG}$, et al. Uterine artery Doppler in predicting pregnancy outcome in woman with APLS. Am College of Obs and Gyn 2001;98(2):235-42.

13. Papageorghiou AT, Yu CK, Bindra R, et al. Multicenter screening to preeclampsia and FGR by transvaginal uterine artery Doppler at 23 wks. of gestation. Ultrasound Obstet Gynaecol 2001;18(5):441-9.

14. Campbell S, Pearce JM, Hackett G, et al. Qualitative assessment of uteroplacental blood flow: early screening test for high risk pregnancies. Obs and Gyn 1986;68(5):649-53.

15. Valensise H, Bezzeccheri V, Rizzo G, et al. Doppler velocimetry of the uterine artery as a screening test for gestational hypertension. Ultrasound Obstet Gynecol 1993;3(1):18-22.

16. Conde-Agudelo A, Belizán JM, Lede R, et al. What does an elevated mean arterial pressure in the 2 nd half of pregnancy predict gestational HT/Preeclampsia? Am J Obs Gyn 1993;169(3):509-14. 